\title{
Occupational exposure to cleaning products and asthma in hospital workers
}

Orianne Dumas ${ }^{1,2}$, Carole Donnay $^{3}$, Dick Heederik ${ }^{4}$, Michel Héry ${ }^{5}$, Dominique Choudat ${ }^{3}$, Francine

Kauffmann ${ }^{1,2}$, Nicole Le Moual ${ }^{1,2}$.

1. Inserm, CESP Center for research in Epidemiology and Population Health, Respiratory and Environmental Epidemiology team, F-94807, Villejuif, France.

2. Université Paris-Sud 11, UMRS1018, F-94807, Villejuif, France.

3. Université Paris-Descartes, Sorbonne Paris Cité, AP-HP, Paris, France.

4. IRAS, Utrecht University, Utrecht, Netherlands.

5. Institut National de Recherche et de Sécurité, Vandoeuvre-lès-Nancy, France.

\section{Correspondence:}

Orianne Dumas

Respiratory and environmental Epidemiology

CESP/U 1018 Inserm

16, avenue Paul Vaillant Couturier

94807 Villejuif Cedex, France

Email: orianne.dumas@inserm.fr

Tel: +331455953 57 / Fax: +33145595169

\section{Key words:}

Asthma, healthcare workers, cleaning agents

\section{Word count:}

Total word count (body of the manuscript): 4363 


\section{ABSTRACT}

Objective: Cleaning products may cause work-related asthma, but information regarding the specific exposures involved is scarce. We aimed to determine the associations between current asthma and occupational exposure to cleaning agents in hospital workers.

Methods: Analyses were conducted in 179 (136 women) hospital workers and a reference population of 545 subjects (18-79 years) from the French case-control and familial Epidemiological study on the Genetics and Environment of Asthma (2003-2007). Exposures to cleaning agents were estimated using 3 methods: self-report, expert assessment, and an asthma-specific job-exposure matrix (JEM). Associations between cleaning products and current asthma were evaluated by logistic regressions, stratified by sex and adjusted for age and smoking status.

Results: According to expert assessment, $55 \%$ of male and $81 \%$ of female hospital workers were exposed to cleaning/disinfecting tasks weekly $(p<0.001)$. No association was observed between cleaning/disinfecting tasks and current asthma in men or in women whatever the assessment method used. In women, exposure to decalcifiers (expert assessment) was associated with current asthma (Odds-ratio (95\% confidence interval):2.38(1.06-5.33)). In hospital workers classified as exposed according to both the expert assessment and the JEM, additional associations were observed for exposure to ammonia (3.05(1.19-7.82)) and to sprays with moderate/high intensity $(2.87(1.02-8.11))$.

Conclusion: Female hospital workers are often exposed to numerous cleaning products, some of which were markedly associated with current asthma. Low numbers prevented a meaningful analysis in males. Objective and more accurate estimates of occupational exposure to cleaning products are needed to better understand the adverse effects of cleaning products. 
WHAT THIS PAPER ADDS:

- Hospital workers, especially women, experience high exposure level to a wide range of cleaning/disinfecting products suspected to play a role in work-related asthma. Previous studies of this relationship largely relied on self-reported exposure.

- Using an expert assessment alone or combined with an asthma-specific job-exposure matrix, we observed in women associations between current asthma and exposure to decalcifiers, products in spray form and ammonia.

- Personal care workers and cleaners in hospital appeared as a high risk group for asthma related to cleaning products. 


\section{INTRODUCTION}

There is growing evidence of a deleterious role of cleaning and disinfecting products in asthma and respiratory disorders $[1,2]$. Exposure to cleaning and disinfecting products is common, both at the workplace in various occupations and industries, and at home during domestic cleaning [2]. Healthcare professionals and hospital workers may experience particularly high exposure level to a wide range of cleaning/disinfecting tasks and products [3], in the frame of prevention against healthcare-related infections. Healthcare workers were identified as an occupational group at risk for asthma in population-based [4-6] and surveillance studies [7-9]. Among healthcare workers with work-related asthma, cleaning and disinfecting products were the most frequently reported agents associated with symptoms $[8,9]$. Occupational exposures to cleaning agents were associated with new-onset asthma in nursing professionals $[10,11]$, with work-related and work-exacerbated asthma symptoms in healthcare professionals [12], and with current asthma in hospital cleaners [13].

Most cleaning products suspected to be associated with asthma are assumed to act as respiratory irritants (e.g. bleach, ammonia, formaldehyde) but some have sensitizing potential (e.g. formaldehyde, perfumed products) [2, 12-15]. The role of products used in spray-form has been emphasized as well $[11,16-18]$, with possibly both irritant and sensitizing mechanisms. Nonetheless, determining the specific tasks and products causing asthma onset or symptoms remains a challenge, partly because of issues related to exposure assessment $[3,19]$. Self-report has been widely used in studies of occupational or domestic cleaning and asthma. However, it has been recently shown in the Epidemiological study on the Genetics and Environment of Asthma (EGEA) [20] that hospital workers underestimated their occupational exposure to cleaning products as compared to an expert assessment. Furthermore, the possibility of differential misclassification has been suggested [20, 21]. An asthma-specific job-exposure-matrix (asthma JEM) [22] also provides estimates of exposure to various asthmogens including industrial cleaning/disinfecting products. The asthma JEM was designed to favor specificity over sensitivity [22] as recommended especially when exposure 
prevalence is low [23]. Associations between exposure to cleaning products estimated by the asthma JEM and new-onset asthma [5] and severe asthma [24] have been observed, but this JEM does not provide assessment of exposure to specific cleaning tasks and products.

Occupational exposure to cleaning was assessed in hospital workers using three methods: a detailed job-specific questionnaire, an expert assessment [20] and the asthma JEM [22]. The aim of the current study was to determine the associations between lifetime exposure to cleaning tasks and various cleaning products in hospital workers and current asthma. For this purpose, the three exposure assessment methods were used, independently and combined. 


\section{MATERIAL AND METHODS}

\section{Population}

The French Epidemiological Study on the Genetics and Environment of Asthma (EGEA) combines a case-control and family-based study [25]: at the baseline study (EGEA1, 1991-1995, 2047 participants), adult and child cases with asthma were recruited in chest clinics in five French cities. First degree relatives of cases were invited to participate in the study and population based controls were recruited through electoral rolls for adults and in surgery department for children. The study protocol was approved by the institutional ethics committee and all participants gave written informed consent. The current analysis used the data from the follow-up (EGEA2, 2003-2007). At EGEA2, 92\% of the initial population answered a brief postal questionnaire (see online supplementary figure E1). More detailed information was recorded for 1601 subjects (77\% of the initial population +58 new family members not examined at baseline). Among the 1571 adult participants, occupational data was available for 1477 subjects. Subjects with noncurrent asthma $(n=102)$, aged less than 18 years $(n=3)$, or with missing data $(n=17)$ for the main variable of interest (current asthma) or potential confounder (smoking habits) were excluded from the analyses. Out of the remaining 1355 subjects, subjects who had ever worked in hospital and a reference population (described below) have been selected for the analyses.

\section{Asthma definition}

Asthma characteristics were recorded in standardized international questionnaires. Subjects with asthma were cases recruited at baseline in chest clinics according to a standardized procedure [25], as well as family members or population-based controls who answered positively to one of the two standardized questions: "have you ever had attacks of breathlessness at rest with wheezing?" or "have you ever had asthma attacks?". Current asthma was defined as ever asthma (at EGEA1 or EGEA2) and report of asthma attacks, respiratory symptoms or asthma treatment in the last 12 
months, as previously in EGEA [26] and in the European Community Respiratory Health Survey (ECRHS) [27].

\section{Occupational exposure}

A complete occupational history was recorded by questionnaire. For each job (with duration $\geq 3$ months) or training period (with duration $\geq 1$ month) reported, position, industry and job task were precisely recorded, and a 4-digit code according to the International Standard Classification of Occupation 1988 (ISCO-88) was assigned by an experienced coder [28]. Hospital workers and cleaners were further asked to answer job-specific questionnaires regarding exposure to cleaning/disinfecting tasks and products, and an expert assessment of exposure was conducted in 179 (43 men, 136 women) hospital workers (healthcare workers or cleaners in hospitals) [20].

Estimation of exposure to various cleaning/disinfecting products by self-report in hospital workers

The two job-specific questionnaires for healthcare workers and cleaners have been previously described in EGEA [20] and were adapted from the ECRHS questionnaire [11]. Briefly, questions regarded the frequency (never, $<1$ day/week, 1-3 days/week, 4-7 days/week) of cleaning/disinfecting tasks, use of cleaning/disinfecting products and use of latex gloves (healthcare workers only) in the relevant jobs. The participants who had several jobs with similar tasks completed the specific questionnaire only once for all similar jobs. In the current study, subjects were classified as exposed to a given task or product according to self-report if the exposure frequency was greater than or equal to once a week, for at least one of the reported jobs.

Estimation of exposure to various cleaning/disinfecting products by expert assessment in hospital workers 
The expert assessment was conducted in hospital workers by an occupational hygienist and two occupational physicians from French hospitals. The assessment procedure has been described previously [20]. Briefly, the probability (non-exposed, $<0.5, \geq 0.5,1$ ), frequency (non exposed, $<1$ day/month, <1 day/week, 1-3 days/week, 4-7 days/week) and intensity (non-exposed, environmental, low, moderate, high) of exposure to cleaning/disinfecting tasks and to 18 specific products were estimated based on job category, hospital unit and calendar year. Self-reported exposure from the specific questionnaire was taken into account in the expert decision as well. In the current study, subjects were classified as exposed to a given task or product if the estimated exposure probability was greater than or equal to 0.5 , and if the exposure frequency was greater than or equal to once a week, for at least one of the reported jobs.

Estimation of exposure cleaning/disinfecting agents by the asthma JEM in all workers

The asthma-specific job-exposure-matrix was set up in the context of the EGEA1 study [22], and has since been largely used in the literature (http://cesp.vjf.inserm.fr/asthmajem). The asthma JEM provides an evaluation (yes/no) of exposure to a list of 22 agents a priori classified as at high or low risk for asthma. To improve exposure assessment, the application of the JEM included an occupational hygiene expert re-evaluation step: occupational exposure or job codes were checked independently by 3 experts for $28 \%$ of all jobs/training periods (in the whole dataset). For jobs with at least one disagreement between experts, the final decision was taken by consensus. In the current study, the asthma JEM was used to estimate lifetime exposure to industrial cleaning/disinfecting products and to latex ( 2 of the 22 listed agents of the JEM) in all subjects.

Estimation of potential exposure to cleaning/disinfecting agents by experts in all workers In addition, potential exposure to cleaning/disinfecting products (yes/no) was evaluated in all subjects by two other experts based on task description in the main occupational questionnaire, available for all workers [20]. As in this case only limited information regarding tasks was available, 
this definition of exposure had a low specificity, and was used only to exclude subjects with potential exposure from the reference category (see below).

\section{Reference category}

In the current study, the reference category (non exposed subjects) corresponded to subjects classified as never exposed according to each of the four following estimation methods: (1) selfreport in job-specific questionnaires for healthcare workers or cleaners; (2) expert assessment in hospital workers; (3) evaluation of potential exposure to cleaning/disinfecting products in all subjects by two experts; (4) asthma JEM (any of the 22 agents). Based on these criteria, the reference group consisted in 545 (212 men, 333 women) subjects without any occupational exposure suspected to be related to asthma.

\section{Statistical analyses}

Associations between current asthma and various cleaning/disinfecting products were studied, using estimation of exposure derived from (1) self-report, (2) the expert assessment and (3) the asthma JEM in hospital workers. Analyses were performed for specific products for which at least 5 subjects with asthma were exposed [22]. According to the expert assessment, 10 products (listed in table 2) fulfilled this condition. According to self-report, only 4 products (bleach, formaldehyde, alcohol, sprays) were analyzed, as exposures to Dakin's solution, chlorexidine, glycol ether and decalcifiers were not assessed by self-report, and exposure to quaternary ammonium compounds and ammonia were reported by too few subjects.

Using information from the expert assessment, analyses have been conducted to determine how the associations with asthma varied with frequency or intensity of exposure, and the number of different products used. Additionally, associations between current asthma and cleaning products in hospital workers classified as exposed according to both the expert assessment and the asthma JEM (industrial cleaning agents) have been assessed. 
Exposure to latex was analyzed separately, and results are presented in online supplement.

Analyses were stratified by sex. For most analyses, too few men were exposed to be studied separately, and results are presented mainly in women. Associations were adjusted for age and smoking status. Further adjustment and effect modification by Body Mass Index (BMI) has been tested in women but led to similar results (not shown). Associations have been evaluated by logistic regression and using a Generalized Estimating Equation approach to account for the familial structure of the data. Analyses have been performed using SAS 9.1. 


\section{RESULTS}

The subjects were aged on average 44.7 years, and subjects with current asthma were significantly younger than subjects without asthma $(p<0.001)$. Detailed clinical characteristics according to asthma status are presented in table E1 (see online supplement). Women working in hospital were significantly less often overweight than women from the reference population, and had similar age and smoking habits (table 1). In men, hospital workers differed from the reference population only in age $(p=0.06)$

According to self-report, $88 \%$ of the women and $80 \%$ of the men working in hospital were exposed weekly to cleaning/disinfecting tasks $(p=0.19)$. According to expert assessment, these proportions were respectively $81 \%$ and $55 \%(p<0.001)$. Among those exposed weekly, women were exposed at higher frequency ( $80 \%$ women exposed 4-7 days/week vs. 68\% men, $p=0.22$ ) and at significantly higher intensity ( $57 \%$ women with moderate to high intensity vs. $23 \%$ men, $p=0.004$ ) compared to men.

According to the asthma JEM, 44 women (32.4\%) and 7 men (16.3\%) working in hospital were classified as exposed to industrial cleaning agents. Most of them (76.5\%) were "institution based personal care workers" (ISCO-88 classification), and the others (23.5\%) were "helpers and cleaners in offices, hotels and other establishments". Overall, the subgroup of women classified as exposed according to the asthma JEM was more often exposed (according to expert assessment) to cleaning/disinfecting tasks (93\% weekly) than those not classified as exposed by the asthma JEM (75\% weekly, $p=0.01)$. A significant difference between these two groups was observed for the use ( $\geq$ 1 day/week) of decalcifiers (50\% vs. $2 \%, p<0.0001)$, ammonia ( $41 \%$ vs. $10 \%, p<0.0001$ ), chlorexidine (45\% vs. $16 \%, p=0.001)$, sprays ( $59 \%$ vs. $36 \%, p=0.01)$, bleach $(60 \%$ vs. $41 \%, p=0.04)$, and Dakin's solution ( $29 \%$ vs. $14 \%, p=0.05)$. 


\section{Cleaning/disinfecting tasks and products and current asthma}

In men, no association was observed between exposure to cleaning/disinfecting tasks and current asthma, according to self-report (odds ratio (95\% confidence interval): $0.73(0.34-1.58)$ ) or expert assessment $(0.62(0.23-1.66))$. Too few subjects were exposed according to the asthma JEM to perform separate analyses for men.

In women, cleaning/disinfecting tasks were not associated with current asthma, according to both self-report $(1.14(0.69-1.87))$ and expert assessment $(1.04(0.64-1.70))$. Exposure to cleaning products according to the asthma JEM was not significantly associated with current asthma (1.75 $(0.87-3.52), p=0.12)$. Associations between specific cleaning products (according to self-report or expert assessment) and current asthma are presented in women (table 2). Exposure to decalcifiers estimated by the expert assessment was significantly associated with current asthma. No significant association was observed with any other cleaning product studied.

\section{Level of exposure to cleaning/disinfecting tasks and products according to expert assessment}

\section{and current asthma}

In women, the number of different products used weekly (expert assessment) varied from 1 to 9 (out of 10 products included), and the median was 4 . No association was observed between the number of products used and current asthma (<4 products: $0.77(0.39-1.56) ; \geq 4$ products: $1.11(0.64-$ 1.92)). Analyses taking into account the number of different products used at a moderate to high intensity did not show significant associations neither (not presented).

The frequency of cleaning task or use of cleaning products according to the expert assessment in the 136 female hospital workers is presented in figure 1 . The products most commonly used according to the expert assessment were alcohol (84\%) and quaternary ammonium compounds (71\%). The highest frequency of exposure (4-7 days/week) was observed in most women classified as exposed ( $\geq$ 1 day/week), for each task or product studied. In analyses of the associations between current 
asthma and exposure to cleaning tasks or products 4-7 days/week, only slightly higher and nonsignificant Odds Ratios (OR) were observed (not shown).

In analyses taking intensity of exposure into account (table 3), OR were increased for moderate to high intensity of exposure to cleaning/disinfecting tasks, bleach, and quaternary ammonium compounds, and an OR of 2.06 was observed for sprays $(p=0.10)$, but no significant association was observed. For ammonia and decalcifiers, all exposed subjects had a low intensity of exposure.

Cleaning/disinfecting task and products and current asthma in hospital workers classified as exposed according to both the expert assessment and the asthma JEM

When limiting the exposed group to the subgroup of hospital workers classified as exposed according to both the expert assessment and the asthma JEM (industrial cleaning products), significant associations were observed between current asthma and exposure of moderate to high intensity to cleaning/disinfecting tasks $(2.32(1.11-4.86))$ and sprays $(2.87(1.02-8.11)$, as shown in table 3 . Exposures (of low intensity for all exposed subjects) to ammonia (3.05 (1.19- 7.82)) and decalcifiers (2.32 (1.01 - 5.31)) were associated with current asthma as well. Although non-significant, ORs close to 2 were observed (see table 3 ) for exposure of moderate to high intensity to bleach $(p=0.09)$ and quaternary ammonium compounds $(p=0.12)$.

A similar analysis using a combination of self-report and the asthma JEM to assess occupational exposure is presented in online supplement (table E2). Although no association reached significance, elevated OR were observed for the use of bleach and sprays. 


\section{DISCUSSION}

This study investigated the associations between current asthma and exposure to various cleaning and disinfecting products, using 3 exposure assessment methods: self-report, an expert assessment and a job-exposure matrix, in female hospital workers. Exposure to decalcifiers estimated by expert assessment was associated with current asthma. In a subgroup of hospital workers, classified as exposed according to the asthma JEM and mainly constituted of personal care workers, marked associations were additionally observed between current asthma and general cleaning/disinfecting tasks, products in spray form and ammonia.

We used an expert assessment to estimate exposure to cleaning and disinfecting products for the first time. We also used the asthma JEM as a complementary method to refine exposure assessment. Self-reported exposure has been widely used in previous studies of the relationship between cleaning products and asthma. Using self-report allow covering a wide range of exposures over specific periods, but has important limits as it may rely on recall, personal knowledge, perception or health status of the subjects. In a previous study in EGEA [20], we showed that hospital workers (especially nurses, auxiliary nurses and cleaners) underestimated their occupational exposure as compared to the expert assessment, though variations were observed according to the type of cleaning products. Underestimation was particularly high for formaldehyde, ammonia and quaternary ammonium compounds. For these agents, self-reported exposure seems highly unreliable, and led in the current analysis to low numbers in the exposed groups, limiting the analyses using self-reports. Further, differential misclassification in self-reported exposure was shown [20], in particular for the use of bleach, underlying the relevance of expert assessment to study this product as well. In addition, the expert assessment provides a more complete evaluation of exposure, as it can include information regarding intensity of exposure, and exposure to some products which are not in the usual specific questionnaires. Expert assessment is often considered as 
the best individual-based approach to estimate occupational exposures in case-control studies [29], though its reliability strongly depends of the experts' competency, the available information regarding job and task description, and the studied agent [30]. To our knowledge, no study investigated the validity of expert-assessment for cleaning products specifically. However, the approach chosen here was favorable to a good reliability: detailed information was available regarding work tasks, unit, periods, etc..; assessment of hospital workers' exposure was done in the experts' area of expertise; and standardized decision rules were set up (see [20] for a more complete discussion). Yet, the expert assessment alone was probably not specific enough, and some products were associated with asthma only in those further classified as exposed by the JEM. The asthma JEM was designed to be highly specific and, to limit exposure misclassification, a job-by-job exposure reevaluation step (for some jobs needing a check) was conducted [22]. Although associations between exposure to asthmagens evaluated by the JEM (including cleaning products) and asthma have been observed in previous studies [5, 24], the asthma JEM provided limited information regarding exposure (active chemical). A JEM focused on occupational exposure among hospital workers (including cleaning products) used previously in a U.S. population [21] also remains with classification into broad categories.

Thus, regarding future research, improvement of occupational exposure assessment is warranted. The use of self-reported exposure alone is discouraged. In epidemiological studies of occupational risk factors for cancer, self-report is rarely used alone [29, 30]. Expert-assessment is expensive and hardly realizable in large studies, which are needed to properly evaluate the effects of the numerous chemical components of cleaning products. JEMs are an alternative, but designing a JEM efficiently assessing exposure to various specific cleaning products is challenging. Beyond practical questions, which of both methods (JEM or expert assessment) is the "best" to evaluate occupational exposure is intensively debated, but comparison studies have been conducted mainly in the field of occupational cancer epidemiology, and the lack of gold-standard hampers a proper validation of each method. New methods to assess exposure to cleaning products need to be developed. Task-based 
assessments have shown that exposure level varied with both the product formulation and the application procedure [3]. More studies are needed, including quantitative exposure measurement [19], to better determine which type of tasks, work practices, ambient environmental conditions and ventilation influence exposure levels [29]. Such measurement may serve as gold-standard to evaluate the validity of existing methods, such as expert-assessment. They may further allow the development of convenient tools for application in larger epidemiological studies such as cleaning-specific JEM or, likely more efficient for cleaning products, task-exposure matrices (TEM) [31].

The associations observed in the current study may reflect occupational asthma as well as workexacerbated asthma, which may both be related to cleaning exposure $[2,8,12]$. Lifetime exposure was used rather than current exposure. This choice was related to power issue (few subjects were currently exposed to cleaning products), but also aimed to reduce the healthy worker survivor effect bias [32]. However, estimation of exposure to various cleaning products was available only for jobs held at least 3 months. Thus, a possible selection of non-exposed jobs by subjects who were exposed during short-term occupations may have impacted the results [33]. In addition, as subjects with childhood onset asthma were included, a healthy worker hire effect may be present [28], and some associations may be underestimated [32].

In this study, exposure to cleaning products in hospital workers affected in large majority women. We considered that in studies of such gender-related activity, analyses stratified on gender were more relevant $[34,35]$. Both the characteristics of exposure, even within a job [36, 37], and effects resulting from exposure might differ between men and women. In men, no association between asthma and cleaning products was suggested, but a meaningful analysis was not possible because of low numbers. Few studies report associations between cleaning products and asthma separately in 
men and women $[17,38,39]$, with varying results according to asthma definition, type of products or task studied.

In women, the use of decalcifiers, estimated by expert assessment, was associated with elevated risks of asthma in the current study. To our knowledge, this relationship has not been reported previously. Two studies based on self-reported exposure investigated the role of decalcifiers in asthma in subjects cleaning their own home [17] or in women employed in domestic cleaning [16], and found no positive association. However, this relationship had never been investigated in healthcare workers. Decalcifiers are acids and may have irritative properties $[14,40]$. The use of hydrochloric acid was associated with asthma symptoms in a previous study of cleaning workers [13]. Mixing acids with bleach may results into serious inhalation accidents, a possible cause of acute irritant-induced asthma (also named reactive airway dysfunction syndrome). An effect of lower level but repeated exposure to irritants on asthma is also increasingly discussed [41]. Whether product mixing was a common practice in hospital workers could hardly be evaluated by expert-assessment. Experience of serious inhalation accidents (to vapors, dust, gases or fumes) was assessed by questionnaire but was reported by only 4 hospital workers in our study.

Among hospital workers, subjects classified as exposed according to the asthma JEM were working as personal care workers or cleaners. In these workers, when combining information from the expert assessment and the JEM, an association with asthma was observed for high intensity of exposure to cleaning/disinfecting tasks overall. The association with decalcifiers was confirmed, and additionally, significant associations were observed for the use of sprays and ammonia, and associations were suggested with the use of bleach, and quaternary ammonium compounds. The relationship between the use of cleaning sprays and asthma has been reported previously, both in domestic $[17,18]$ and occupational setting $[11,16]$. The high potential for inhalation exposure associated with product spraying was underlined in a study characterizing qualitatively airborne exposures during cleaning 
tasks in hospital workers [3]. In the current study, moderate to high intensity of exposure to cleaning sprays was associated with current asthma, consistently with a dose-response relationship previously observed for the use of cleaning sprays at home [17]. Previous studies have reported associations between asthma and self-reported use of bleach and ammonia $[11,12,16]$. Several case-report of occupational asthma related to quaternary ammonium compounds have been published [14], but this relationship has not been previously reported in epidemiological studies. However, as stated above, studies based on self-reported exposure may be inadequate for these agents. A surveillance study of work-related asthma trends in France over the period 2001-2009 showed a significant increase of cases of work-related asthma linked to quaternary ammonium compounds, particularly in healthcare workers [42]. In the current study, numbers were low and the association with asthma did not reach significance, but the elevated odds-ratio (1.93) suggests that particular attention should be paid to these agents in future research.

In the current study, associations between cleaning products and asthma were not importantly modified after taking into account higher frequency of exposure and the number of different products used. Power issues have limited the possibility to investigate dose-response relationships. The fact that we observed associations with asthma mainly in the subgroup classified as exposed according to the JEM suggests that personal care workers (auxiliary nurses) and cleaners in hospital may constitute a high risk group for asthma related to cleaning products compared to other hospital workers. The highly specific assessment provided by the job-exposure matrix (only jobs with high probability of exposure to industrial cleaning products were classified as exposed) may have favored the detection of associations with asthma [23]. Alternatively, the observed associations may be related to specific cleaning tasks and work environment [3] associated with these jobs. A previous study in healthcare workers found similarly that nurses (with a large definition including for instance nurses' aides) had an increased risk of asthma related to cleaning compared to other healthcare professionals [10]. 
Multiple exposures are a complicating issue, which is particularly present in studies of occupational hazards in healthcare workers [43]. Some of the associations we found might be inter-related with other exposures or observed by chance, and low numbers limited the possibility to address this point. However, as shown above, most of the observed associations are consistent with previous studies or with hypotheses formulated in the literature.

\section{Conclusion}

In conclusion, this study adds evidence to the burden of work-related asthma due to cleaning products. We have shown that female hospital workers, in particular personal care workers and cleaners, are exposed to numerous cleaning products, some of which were associated with current asthma. We used a combination of three methods to evaluate exposure (self-report, expert assessment, both based on responses to a detailed specific questionnaire and an asthma-specific JEM). The results strengthen evidence of a deleterious role of some agents (sprays, ammonia) previously observed in studies based only on self-reported exposure, and suggest associations not previously reported (decalcifiers). This study underlined the need for objective and more accurate estimates of occupational exposure to cleaning products, that take into account the specificity of each cleaning job and task, in order to progress in the understanding of the adverse respiratory effect of cleaning products. 


\section{ACKNOWLEDGEMENT}

\section{EGEA cooperative group:}

Coordination: F Kauffmann; F Demenais (genetics); I Pin (clinical aspects).

Respiratory epidemiology: Inserm U 700, Paris M Korobaeff (Egea1), F Neukirch (Egea1); Inserm U 707, Paris : I Annesi-Maesano ; Inserm CESP/U 1018, Villejuif : F Kauffmann, N Le Moual, R Nadif, MP Oryszczyn ; Inserm U 823, Grenoble : V Siroux

Genetics: Inserm U 393, Paris : J Feingold ; Inserm U 946, Paris : E Bouzigon , F Demenais, MH Dizier ; CNG, Evry : I Gut , M Lathrop.

Clinical centers: Grenoble : I Pin, C Pison; Lyon : D Ecochard (Egea1), F Gormand, Y Pacheco ; Marseille : D Charpin (Egea1), D Vervloet ; Montpellier : J Bousquet ; Paris Cochin : A Lockhart (Egea1), R Matran (now in Lille) ; Paris Necker : E Paty, P Scheinmann ; Paris-Trousseau : A Grimfeld, J Just.

Data and quality management: Inserm ex-U155 (Egea1) : J Hochez ; Inserm CESP/U 1018, Villejuif : N Le Moual, Inserm ex-U780 : C Ravault ; Inserm ex-U794 : N Chateigner ; Grenoble : J Ferran

The authors thank all those who participated to the setting of the study and on the various aspects of the examinations involved: interviewers, technicians for lung function testing and skin prick tests, blood sampling, IgE determinations, coders, those involved in quality control, data and sample management and all those who supervised the study in all centers. The authors are grateful to the three $\mathrm{CIC}$-Inserm of Necker, Grenoble and Marseille who supported the study and in which subjects were examined. They thank M-A Denis (Hospices Civils de Lyon, Groupement hospitalier Est, Médecine du Personnel, Bron, France) and R. Magis (Service Central de Medicine du Travail, AP-HP, Paris, France) for the expert assessment of exposure in hospital workers; J. Fevotte (Institut de Veille Sanitaire, Département Santé Travail, Saint Maurice, France) and N. Massin (INRS, Département Epidémiologie en Entreprise, Vandoeuvre-lès-Nancy, France) for the expert assessment of potential exposure to cleaning/disinfecting tasks in all subjects; and G. Vasseur (Inserm U780, Villejuif, France) 
for job coding. They are indebted to all the individuals who participated without whom that study would not have been possible.

\section{COMPETING INTERESTS}

None.

\section{FUNDING}

French Agency of health safety, environment and work (AFSSET-EST-09-15); Hospital program of clinical research (PHRC)-Paris; National Research Agency - Health environment, health-work program (ANR-SEST 2005); Merck Sharp \& Dohme (MSD); Isere committee against respiratory diseases (COMARES); French Ministry of foreign and European affairs / Netherland organization for scientific research (NWO) Van Gogh program for French Dutch cooperation; and the University Paris Sud 11 ED420 doctoral grant.

\section{LICENCE STATEMENT}

The Corresponding Author has the right to grant on behalf of all authors and does grant on behalf of all authors, an exclusive licence (or non-exclusive for government employees) on a worldwide basis to the BMJ Group and co-owners or contracting owning societies (where published by the BMJ Group on their behalf), and its Licensees to permit this article (if accepted) to be published in Occupational and Environmental Medicine and any other BMJ Group products and to exploit all subsidiary rights, as set out in our licence. 
Table 1. Description of the population

\begin{tabular}{|c|c|c|c|c|}
\hline & \multicolumn{2}{|c|}{ Men } & \multicolumn{2}{|c|}{ Women } \\
\hline & Reference population & Hospital workers & Reference population & Hospital workers \\
\hline Age, $m(S D)$, years & $43.0(16.8)$ & $48.3(15.5)$ & $44.8(15.5)$ & $45.9(13.7)$ \\
\hline \multicolumn{5}{|l|}{ Smoking habits, \% } \\
\hline No smoker & 43.4 & 44.2 & 59.8 & 56.6 \\
\hline Ex-smoker & 27.8 & 30.2 & 22.8 & 26.5 \\
\hline Current smoker & 28.8 & 25.6 & 17.4 & 16.9 \\
\hline Expert assessment: exposed to cleaning/disinfecting tasks, \% & - & $55.0+$ & - & 80.9 \\
\hline Asthma JEM: exposed to cleaning products, $\%$ & - & 16.3 & - & 32.4 \\
\hline
\end{tabular}

${ }^{*} p<0.05,{ }^{* *} p<0.01$ compared to the reference population. + Missing for $n=3$ men. $¥$ Missing for $n=16$ women. 
Table 2. Associations between exposure to cleaning task and use of cleaning products according to self-report and expert assessment in hospital workers and current asthma in women

\begin{tabular}{|c|c|c|c|c|}
\hline & \multicolumn{2}{|c|}{ Self-report, exposed $\geq 1$ day/week } & \multicolumn{2}{|c|}{ Expert assessment, exposed $\geq 1$ day/week } \\
\hline & $\mathrm{n}:$ As-/As+ & Adjusted* OR (95\% Cl) & $\mathrm{n}: \mathrm{As}-/ \mathrm{As}+$ & Adjusted* OR $(95 \% \mathrm{Cl})$ \\
\hline Cleaning / disinfecting tasks & $68 / 37$ & $1.14(0.69-1.87)$ & $74 / 36$ & $1.04(0.64-1.70)$ \\
\hline Dakin's solution ${ }^{+}$ & - & - & $24 / 9$ & $0.92(0.39-2.15)$ \\
\hline Quaternary ammonium & $9 / 3$ & - & $65 / 31$ & $0.96(0.58-1.61)$ \\
\hline Chlorexidine + & - & - & $35 / 13$ & $0.77(0.39-1.52)$ \\
\hline Ammonia & $3 / 1$ & - & $14 / 13$ & $1.87(0.83-4.21)$ \\
\hline Glycol ether ${ }^{+}$ & - & - & $8 / 6$ & $1.27(0.43-3.76)$ \\
\hline Sprays & $33 / 24$ & $1.36(0.74-2.50)$ & $36 / 23$ & $1.21(0.67-2.18)$ \\
\hline Decalcifiers ${ }^{+}$ & - & - & $11 / 13$ & $2.38(1.06-5.33)$ \\
\hline
\end{tabular}

As-, never asthma; As+, current asthma; $\mathrm{Cl}$, Confidence Interval; JEM, job-exposure matrix; OR, Odds-Ratio.

* Adjusted for age and smoking habits, and taking into account familial dependence. † Dakin's solution, Chlorexidine, Glycol Ether: not assessed by selfreport (not in job-specific questionnaires); Decalcifiers: assessed by self-report only in the job-specific questionnaire for cleaners (too few subjects to perform the analysis with self-reported exposure). 


$\left.\begin{array}{|r|r}100 \% \\ 90 \% \\ 80 \% \\ 70 \% \\ 60 \% \\ 50 \% \\ 40 \% \\ 30 \% \\ 20 \% \\ 10 \% \\ 0 \%\end{array}\right]$

Figure 1. Frequency of cleaning task or use of cleaning products according to expert assessment in female hospital workers.

The expert assessment procedure has been described in detail by Donnay et al. [20] 
Table 3. Associations between current asthma and intensity of exposure to cleaning task and products in female hospital workers, according to the expert assessment alone and combined with asthma JEM

\begin{tabular}{|c|c|c|c|c|}
\hline & \multicolumn{2}{|c|}{ Expert assessment } & \multicolumn{2}{|c|}{ Expert assessment + asthma JEM } \\
\hline & $\mathrm{n}:$ As-/As+ & Adjusted* OR (95\% Cl) & $\mathrm{n}:$ As-/As+ & Adjusted* OR $(95 \% \mathrm{Cl}$ \\
\hline Non exposed (ref.) & $222 / 111$ & 1 & 222 / 111 & 1 \\
\hline \multicolumn{5}{|l|}{ Cleaning / disinfecting task } \\
\hline Low or environmental intensity & $36 / 11$ & $0.65(0.31-1.37)$ & $5 / 2$ & - \\
\hline Moderate to high intensity & $37 / 25$ & $1.45(0.81-2.62)$ & $16 / 18$ & $2.32(1.11-4.86)$ \\
\hline \multicolumn{5}{|l|}{ Bleach } \\
\hline Low or environmental intensity & $30 / 7$ & $0.56(0.24-1.32)$ & $5 / 2$ & - \\
\hline Moderate to high intensity & $15 / 12$ & $1.60(0.74-3.46)$ & $9 / 10$ & $2.11(0.88-5.03)$ \\
\hline \multicolumn{5}{|l|}{ Quaternary ammonium } \\
\hline Low or environmental intensity & $35 / 10$ & $0.59(0.28-1.22)$ & $4 / 2$ & - \\
\hline Moderate to high intensity & $30 / 21$ & $1.39(0.73-2.66)$ & $14 / 15$ & $1.93(0.85-4.40)$ \\
\hline \multicolumn{5}{|l|}{ Alcohol } \\
\hline Low or environmental intensity & $23 / 11$ & $0.94(0.44-1.98)$ & $8 / 7$ & $1.66(0.62-4.48)$ \\
\hline Moderate to high intensity & $57 / 23$ & $0.86(0.49-1.51)$ & $13 / 9$ & $1.21(0.47-3.09)$ \\
\hline \multicolumn{5}{|l|}{ Sprays } \\
\hline Low or environmental intensity & $26 / 10$ & $0.75(0.34-1.65)$ & $7 / 6$ & $1.51(0.46-4.98)$ \\
\hline Moderate to high intensity & $10 / 12$ & $2.06(0.87-4.88)$ & $5 / 8$ & $2.87(1.02-8.11)$ \\
\hline
\end{tabular}

As-, never asthma; As+, current asthma; $\mathrm{Cl}$, Confidence Interval; JEM, Job-Exposure Matrix; OR, Odds-Ratio.

* Adjusted for age and smoking habits, and taking into account familial dependence.

Exposure to Dakin's solution, chlorexidine, formaldehyde, glycol ether: two few subjects exposed to perform the analyses. Exposure to ammonia and decalcifiers: all exposed subjects were at low or environmental intensity of exposure. 


\section{REFERENCES}

1. Jaakkola JJ, Jaakkola MS. Professional cleaning and asthma. Curr Opin Allergy Clin Immunol 2006;6:85-90.

2. Zock JP, Vizcaya D, Le Moual N. Update on asthma and cleaners. Curr Opin Allergy Clin Immunol 2010;10:114-20.

3. Bello A, Quinn MM, Perry MJ, et al. Characterization of occupational exposures to cleaning products used for common cleaning tasks--a pilot study of hospital cleaners. Environ Health 2009;8:11.

4. Bang KM, Hnizdo E, Doney B. Prevalence of asthma by industry in the US population: a study of 2001 NHIS data. Am J Ind Med 2005;47:500-8.

5. Kogevinas M, Zock JP, Jarvis D, et al. Exposure to substances in the workplace and new-onset asthma: an international prospective population-based study (ECRHS-II). Lancet 2007;370:336-41.

6. McHugh MK, Symanski E, Pompeii LA, et al. Prevalence of asthma by industry and occupation in the U.S. working population. Am J Ind Med 2010;53:463-75.

7. Kopferschmitt-Kubler MC, Ameille J, Popin E, et al. Occupational asthma in France: a 1-yr report of the observatoire National de Asthmes Professionnels project. Eur Respir J 2002;19:84-9.

8. Liss GM, Buyantseva L, Luce CE, et al. Work-related asthma in health care in Ontario. Am J Ind Med 2011;54:278-84.

9. Pechter E, Davis LK, Tumpowsky C, et al. Work-related asthma among health care workers: surveillance data from California, Massachusetts, Michigan, and New Jersey, 1993-1997. Am J Ind Med 2005;47:265-75.

10. Arif AA, Delclos GL, Serra C. Occupational exposures and asthma among nursing professionals. Occup Environ Med 2009;66:274-8.

11. Mirabelli MC, Zock JP, Plana E, et al. Occupational risk factors for asthma among nurses and related healthcare professionals in an international study. Occup Environ Med 2007;64:474-9.

12. Arif AA, Delclos GL. Association between cleaning-related chemicals and work-related asthma and asthma symptoms among healthcare professionals. Occup Environ Med 2012;69:35-40.

13. Vizcaya D, Mirabelli MC, Anto JM, et al. A workforce-based study of occupational exposures and asthma symptoms in cleaning workers. Occup Environ Med 2011;68:914-9.

14. Quirce S, Barranco P. Cleaning agents and asthma. J Investig Allergol Clin Immunol 2011;20:542-50.

15. Chan-Yeung M, Malo JL. Aetiological agents in occupational asthma. Eur Respir J 1994;7:346-

71.

16. Medina-Ramon M, Zock JP, Kogevinas M, et al. Asthma, chronic bronchitis, and exposure to irritant agents in occupational domestic cleaning: a nested case-control study. Occup Environ Med 2005;62:598-606.

17. Zock JP, Plana E, Jarvis D, et al. The use of household cleaning sprays and adult asthma: an international longitudinal study. Am J Respir Crit Care Med 2007;176:735-41.

18. Le Moual N, Varraso R, Siroux V, et al. Domestic use of cleaning sprays and asthma activity in women. Eur Respir J 2012 (in press).

19. Bello A, Quinn MM, Perry MJ, et al. Quantitative assessment of airborne exposures generated during common cleaning tasks: a pilot study. Environ Health 2010;9:76.

20. Donnay C, Denis MA, Magis R, et al. Under-estimation of self-reported occupational exposure by questionnaire in hospital workers. Occup Environ Med 2011;68:611-7.

21. Delclos GL, Gimeno D, Arif AA, et al. Occupational exposures and asthma in health-care workers: comparison of self-reports with a workplace-specific job exposure matrix. Am J Epidemiol 2009;169:581-7. 
22. Kennedy SM, Le Moual N, Choudat D, et al. Development of an asthma specific job exposure matrix and its application in the epidemiological study of genetics and environment in asthma (EGEA). Occup Environ Med 2000;57:635-41.

23. Kromhout $\mathrm{H}$, Vermeulen R. Application of job-exposure matrices in studies of the general population: some clues to their performance. Eur Respir Rev 2001;11:80-90.

24. Le Moual N, Siroux V, Pin I, et al. Asthma severity and exposure to occupational asthmogens. Am J Respir Crit Care Med 2005;172:440-5.

25. Kauffmann F, Dizier MH, Pin I, et al. Epidemiological study of the genetics and environment of asthma, bronchial hyperresponsiveness, and atopy: phenotype issues. Am J Respir Crit Care Med 1997;156:S123-9.

26. Siroux V, Boudier A, Bousquet J, et al. Phenotypic determinants of uncontrolled asthma. J Allergy Clin Immunol 2009;124:681-7 e3.

27. Cazzoletti L, Marcon A, Janson C, et al. Asthma control in Europe: a real-world evaluation based on an international population-based study. J Allergy Clin Immunol 2007;120:1360-7.

28. Dumas O, Smit LA, Pin I, et al. Do young adults with childhood asthma avoid occupational exposures at first hire? Eur Respir J 2011;37:1043-9.

29. Teschke K, Olshan AF, Daniels JL, et al. Occupational exposure assessment in case-control studies: opportunities for improvement. Occup Environ Med 2002;59:575-93; discussion 94.

30. Bouyer J, Hemon D. Retrospective evaluation of occupational exposures in population-based case-control studies: general overview with special attention to job exposure matrices. Int J Epidemiol 1993;22 Suppl 2:S57-64.

31. Benke $G$, Sim M, Fritschi L, et al. Beyond the job exposure matrix (JEM): the task exposure matrix (TEM). Ann Occup Hyg 2000;44:475-82.

32. Le Moual N, Kauffmann F, Eisen EA, et al. The healthy worker effect in asthma: work may cause asthma, but asthma may also influence work. Am J Respir Crit Care Med 2008;177:4-10.

33. Iwatsubo $\mathrm{Y}$, Matrat $\mathrm{M}$, Brochard $\mathrm{P}$, et al. Healthy worker effect and changes in respiratory symptoms and lung function in hairdressing apprentices. Occup Environ Med 2003;60:831-40.

34. Becklake MR, Kauffmann F. Gender differences in airway behaviour over the human life span. Thorax 1999;54:1119-38.

35. Messing $\mathrm{K}$, Punnett $\mathrm{L}$, Bond $\mathrm{M}$, et al. Be the fairest of them all: challenges and recommendations for the treatment of gender in occupational health research. Am J Ind Med 2003;43:618-29.

36. Eng A, t Mannetje A, McLean D, et al. Gender differences in occupational exposure patterns. Occup Environ Med 2011;68:888-94.

37. Calvet B, Riel J, Couture V, et al. Work organisation and gender among hospital cleaners in Quebec after the merger of 'light' and'heavy' work classifications. Ergonomics 2012;55:160-72.

38. de Fatima Macaira E, Algranti E, Medina Coeli Mendonca E, et al. Rhinitis and asthma symptoms in non-domestic cleaners from the Sao Paulo metropolitan area, Brazil. Occup Environ Med 2007;64:446-53.

39. Obadia M, Liss GM, Lou W, et al. Relationships between asthma and work exposures among non-domestic cleaners in Ontario. Am J Ind Med 2009;52:716-23.

40. Zock JP. World at work: cleaners. Occup Environ Med 2005;62:581-4.

41. Quirce S, Barranco P. Cleaning agents and asthma. J Investig Allergol Clin Immunol 2010;20:542-50.

42. Paris C, Ngatchou-Wandji J, Luc A, et al. Work-related asthma in France: recent trends for the period 2001-2009. Occup Environ Med Published online first: 3 March 2012. doi: 10.1136/oemed2011-100487.

43. Zock JP, Cavalle $\mathrm{N}$, Kromhout $\mathrm{H}$, et al. Evaluation of specific occupational asthma risks in a community-based study with special reference to single and multiple exposures. J Expo Anal Environ Epidemiol 2004;14:397-403. 